\title{
Hepatitis B Virus Can Be Sensed by STING- dependent DNA Sensors but Suppresses the DNA Sensing Pathway in Humans with Acute and Chronic Hepatitis B Virus Infection
}

\section{Hongtao Chen}

Southern Medical University Nanfang Hospital https://orcid.org/0000-0002-1020-7131

Guirong He

Shenzhen People's Hospital

Yue Chen

Shenzhen People's Hospital

Xiaoyong Zhang ( $\sim$ xiaoyzhang@smu.edu.cn )

https://orcid.org/0000-0002-6930-9423

Research

Keywords: Hepatitis B virus, DNA sensor, innate immunity, hepatitis B

Posted Date: February 12th, 2020

DOl: https://doi.org/10.21203/rs.2.23304/v1

License: (c) (1) This work is licensed under a Creative Commons Attribution 4.0 International License.

Read Full License 


\section{Abstract}

Background: With the discovery of stimulator of interferon genes (STING) in 2008, many intracellular molecules have been identified as STING-dependent DNA sensors in recent years. Studies show the DNA sensor-STING-IFN- $\beta$ pathway plays an important role in defense against viral infections. However, the recognition of hepatitis B virus (HBV) by DNA sensors is still largely unclear. In this study, we aimed to investigate the role of STING-dependent DNA sensors in HBV infection. Methods: The expression of these DNA sensors in PBMCs from patients with acute and chronic HBV infection was analyzed by quantitative real-time PCR. The cellular source of the upregulated DNA sensor and the response of the corresponding sensing pathway in PBMCs from HBV-infected patients were also investigated. Results: The expression of interferon gamma inducible protein 16 (IFI16), DEAD-box polypeptide 41 (DDX41), meiotic recombination 11 homolog A (MRE11), and STING were upregulated in chronic HBV-infected patients, whereas only IFI16 expression increased in acute HBV-infected patients. However, no IFN- $\beta$ induction was observed in PBMCs in either acute or chronic HBV-infected patients. We next found IFI16 was mainly expressed in monocytes from acute and chronic hepatitis B patients. By stimulation of monocytes with VACV ds 70mer, an agonist ligand for IFI16, we confirmed the suppressed response of the IFI16-STING pathway in chronic HBV infection. Conclusions: Our results suggest that HBV can be sensed by DNA sensors in PBMCs in both acute and chronic HBV-infected patients and meanwhile actively counteract the DNA sensing pathway in PBMCs, which may facilitate the persistence of HBV infection.

\section{Background}

Hepatitis B virus (HBV) is a noncytopathic, hepatotropic DNA virus in humans. Infection with HBV results in acute or chronic hepatitis B. About 248 million people globally are chronically infected with HBV and at high risk for liver cirrhosis and hepatocellular carcinoma [1]. The mechanism of development of chronicity of HBV infection remains to be determined. The host's age and immune status significantly influence the outcome of acute infection, as the rate of chronicity after acute infection is more than $90 \%$ among children younger than 1 year and is less than $5 \%$ among infected adults [2]. Thus, the host immune status appears to be a major determinant of the clinical outcome of HBV infection. Besides, HBV is also referred to as a "stealth" virus that elicits negligible innate immune responses in the early infection phase to facilitate establishment of chronic infection [3]. It is well established that a robust and HBVspecific CD ${ }^{+} T$ cell response is necessary to eliminate HBV infection. In contrast, the contribution of innate immune mechanism is not well understood and whether HBV can be sensed by the innate immune system remains controversial [4-6].

The invasion of mammalian cells by pathogens represents a danger signal for the innate immune system which takes use of pattern-recognition receptors (PRRs) to recognize conserved motifs from the pathogens. The intracellular DNA sensors are responsible for the recognition of cytoplasmic or nuclear pathogen-derived DNA. Recently, DNA-dependent activator of IRFs (DAI), interferon gamma inducible protein 16 (IFI16), DEAD-box polypeptide 41 (DDX41), DNA-dependent protein kinase (DNA-PK), meiotic recombination 11 homolog A (MRE11), and cyclic GMP-AMP synthase (cGAS) were identified as 
intracellular DNA sensors [7]. On binding to foreign DNA, these DNA sensors activate stimulator of interferon genes (STING) [7-8], which then activates TANK-binding kinase 1 (TBK1). TBK1 subsequently phosphorylates STING and the downstream transcription factor interferon regulatory factor 3 (IRF3) to promote expression of type I interferons (IFN-Is) and other cytokines [9-11]. Thus, the DNA sensor-STING pathway plays a significant role in host defense against invading DNA viruses.

Previous studies have suggested that many viral infectious diseases can induce activation of STINGdependent DNA-sensing pathways [12] and meanwhile, some viruses utilize a plethora of mechanisms to antagonize the DNA-sensing pathways [13-15]. However, little is known about the roles of DNA sensors in HBV infection. Our previous study showed IFI16 as a component of inflammasome complexes is upregulated in both acute and chronic HBV infection in humans [16]. In this study, we scrutinized all the known STING-dependent DNA sensors in peripheral blood mononuclear cells (PBMCs) from acute and chronic HBV-infected patients and found again that only IFI16, expressed most frequently in monocytes, is involved in acute and chronic hepatitis B in humans. Furthermore, the IFI16-STING pathway is suppressed in chronic hepatitis B which may contribute to HBV-induced immunotolerance.

\section{Materials And Methods}

\section{Subjects}

From May 2015 to November 2018, 66 treatment-naive patients with chronic HBV infection were recruited at Shenzhen people's hospital (Shenzhen, China). The patients were classified into three groups according to the guidelines for treatment of chronic hepatitis $B$ [17]: immune-tolerant carriers $(I T, n=15)$, HBeAg-positive hepatitis patients $(C H B, n=31)$, and inactive carriers $(I A, n=20)$. Twenty-eight healthy individuals were enrolled as healthy controls $(H C s)$. Patients with acute hepatitis $B(A H B, n=8)$ and varicella $(V Z V, n=8)$ were also included in this study. Patients with any other diseases were excluded. The clinical characteristics of HCs and patients are shown in Tables 1 and 2. This study was approved by the Ethical Committee of Shenzhen people's hospital. All participants signed written informed consent before sample collection. 


\begin{tabular}{|llllll|}
\hline Group & HC & IT & CHB & IA & P-Value \\
\hline$n$ & 28 & 15 & 31 & 20 & - \\
\hline Gender (male/female) & $15 / 13$ & $8 / 6$ & $17 / 14$ & $11 / 9$ & NS $^{\text {a }}$ \\
\hline Age (years) & $25(22-$ & $31(23-45)$ & $32(19-43)$ & $34(25-$ & NS $^{\text {b }}$ \\
\hline $\begin{array}{l}\text { HBV DNA (log } 10 \\
\text { copies/mL) }\end{array}$ & ND) & $7.76(6.06-$ & $7.09(6.02-$ & $<3$ & - \\
\hline ALT (U/L) & $21(11-$ & $23(10-40)$ & $284(105-681)$ & $26(17-$ & P<0.0001 b \\
\hline & $35)$ & & & $38)$ & - \\
\hline HBeAg / anti-HBe & $0 / 0$ & $15 / 0$ & $31 / 0$ & $0 / 20$ & - \\
\hline
\end{tabular}

HC: healthy controls; IT: immune tolerant carriers; CHB: chronic hepatitis B patients; IA: inactive carriers; ALT: alanine aminotransferase; HBeAg: hepatitis B e antigen; ND: not determined; NS: not significant. Values are $n$ or the median with range.

${ }^{\mathrm{a}} \mathrm{Chi}^{2}$ test.

${ }^{\mathrm{b}}$ Kruskal-Wallis $\mathrm{H}$ test.

Table 1 Clinical characteristics of healthy controls and treatment-naive patients with chronic HBV infection

\begin{tabular}{|lllll|}
\hline Group & HC & AHB & VZV & $P$-Value \\
\hline$n$ & 28 & 8 & 8 & - \\
\hline Gender (male / female) & $15 / 13$ & $5 / 3$ & $4 / 4$ & $\mathrm{NS}^{\mathrm{a}}$ \\
\hline Age (years) & $25(22-46)$ & $30(21-45)$ & $32(16-48)$ & $\mathrm{NS}^{\mathrm{b}}$ \\
\hline HBV DNA ( $\log _{10}$ copies $\left./ \mathrm{mL}\right)$ & $\mathrm{ND}$ & $3.44(2.10-5.03)$ & $\mathrm{ND}$ & - \\
\hline ALT $(\mathrm{U} / \mathrm{L})$ & $21(11-35)$ & $517(100-1329)$ & $35(11-63)$ & $P<0.0001^{\mathrm{b}}$ \\
\hline TBil $(\mu \mathrm{mol} / \mathrm{L})$ & $12(6-16)$ & $67(35-125)$ & $11(5-21)$ & $P<0.0001^{\mathrm{b}}$ \\
\hline
\end{tabular}

HC: healthy controls; AHB: acute hepatitis B patients; VZV: varicella patients; ALT: alanine aminotransferase; TBil: total bilirubin; ND: not determined; NS: not significant. Values are $n$ or the median with range. 
${ }^{\text {a }}$ Chi $^{2}$ test.

${ }^{\mathrm{b}}$ Kruskal-Wallis H test.

Table 2 Clinical characteristics of healthy controls and patients with acute HBV infection and varicella

\section{Isolation Of PBMCs And Monocytes}

Blood samples were obtained from each subject. PBMCs were isolated using Ficoll-Paque (GE Healthcare) density gradient centrifugation. CD14 ${ }^{+}$monocytes and non-monocytes were isolated from fresh PBMCs using Dynabeads untouched human monocytes separation kits (Invitrogen, Shanghai, China). FACS analyses showed that the purity of the obtained CD $14^{+}$monocytes was greater than $95 \%$.

\section{RNA extraction, reverse transcription, and quantitative real- time PCR (qPCR)}

Total RNA was extracted from cells with TRIzol (Invitrogen). Target mRNA was reverse transcribed using the PrimeScript RT reagent Kit with gDNA Eraser (TaKaRa). The primer sets used in this study were shown in Table 3. The qPCR was conducted with the SYBR Premix ExTaq kit (TaKaRa) on the Applied Biosystems ViiA 7Dx Real-Time PCR system (Applied Biosystems, Shanghai, China). The standard curve for each target gene was established using gradient dilutions of the corresponding DNA fragments amplified by real-time PCR (RT-PCR). Based on the standard curve, the mRNA copies of each target gene were determined. The qPCR was performed in duplicate for each sample. The expression levels of each target gene were shown as values normalized against human $10^{3}$ copies of GAPDH transcripts. 
Table 3

Primer sequences used for qPCR

\begin{tabular}{|c|c|c|c|}
\hline Gene name & Primer type & Sequence $\left(5^{\prime} \rightarrow 3^{\prime}\right)$ & Amplicon size(bp) \\
\hline \multirow[t]{2}{*}{ IFI16 } & Sense & GAAGTGCCAGCGTAACTCCTAA & \multirow[t]{2}{*}{177} \\
\hline & Antisense & TGATTGTGGTCAGTCGTCCAT & \\
\hline \multirow[t]{2}{*}{ DDX41 } & Sense & TCCGTGAAAGAGCAGATGGAGA & \multirow[t]{2}{*}{90} \\
\hline & Antisense & СTTCTTCTGCAGCAAATCCATGAG & \\
\hline \multirow[t]{2}{*}{ DNA-PK } & Sense & GAAAGTTAGCAGGTGCCAATCCA & \multirow[t]{2}{*}{101} \\
\hline & Antisense & TCGTGCCACAGCCACATAGTC & \\
\hline \multirow[t]{2}{*}{ cGAS } & Sense & GGGAGCTACTATGAGCACGTGAA & \multirow[t]{2}{*}{119} \\
\hline & Antisense & ACAAAGTAATATGCACGAGTGTTGG & \\
\hline \multirow[t]{2}{*}{ MRE11 } & Sense & CTTGAGCATAAGGGTTATTTGAGCA & \multirow[t]{2}{*}{102} \\
\hline & Antisense & CAAGTTCAATAAAGATGTGGGCAGA & \\
\hline \multirow[t]{2}{*}{ DAI } & Sense & TGGGGAGGTGGGATTTAGTG & \multirow[t]{2}{*}{131} \\
\hline & Antisense & TCTGGAAGCAAGCAGGTCAA & \\
\hline \multirow[t]{2}{*}{ STING } & Sense & САСССТТСТССССТТССТТТ & \multirow[t]{2}{*}{133} \\
\hline & Antisense & ССТССТССТССТСТССАТТСТТ & \\
\hline \multirow[t]{2}{*}{ IFN- $\beta$} & Sense & ACAGGTTACCTCCGAAACTGAAGA & \multirow[t]{2}{*}{108} \\
\hline & Antisense & TTAGCCATCAGTCACTTAAACAGCA & \\
\hline \multirow[t]{2}{*}{ GAPDH } & Sense & GCACCGTCAAGGCTGAGAAC & \multirow[t]{2}{*}{138} \\
\hline & Antisense & TGGTGAAGACGCCAGTGGA & \\
\hline
\end{tabular}

\section{Cell Culture And Stimulation}

PBMCs, monocytes, and non-monocytes were cultured at $6 \times 10^{5}$ cells $/ \mathrm{mL}$ in RPMI 1640 containing $10 \%$ FBS, $2 \mathrm{mmol} / \mathrm{L} \mathrm{L}$-glutamine, $100 \mu \mathrm{g} / \mathrm{mL}$ streptomycin, and $100 \mathrm{U} / \mathrm{mL}$ penicillin at $37^{\circ} \mathrm{C}$ in $5 \% \mathrm{CO}_{2}$ incubator. The fresh cells were cultured for 2 hours and then stimulated with VACA ds 70 mer (InvivoGen) at a concentration of $2 \mu \mathrm{g} / \mathrm{mL}$ for 24 hours according to the manufacturer's instructions. The mRNA expression of IFI16, STING, and IFN- $\beta$ was detected by qPCR.

\section{HBV DNA assays and serological assays}


Serum HBV DNA loads were quantified on the ABI 7500 Real-time PCR System (Applied Biosystems). The serum levels of hepatitis B surface antigen ( $\mathrm{HBsAg})$, hepatitis B e antigen ( $\mathrm{HBeAg})$, and anti-HBe were determined with electrochemiluminescence immunoassay on the Roche Diagnostics Cobas e601 analyzer (Roche Diagnostics, Germany). The normal range of serum ALT was 0 to $40 \mathrm{U} / \mathrm{L}$.

\section{Statistical analysis}

Data were expressed as mean \pm SD. GraphPad Prism 8 software was used for statistical analysis. The Student's $t$ test was used for comparing the means of two groups. When comparing more than two groups, analyses were conducted using one-way ANOVA, followed by the Bonferroni post hoc test. $\mathrm{p}<$ 0.05 was considered significant.

\section{Results}

\section{IFI16 expression is upregulated in PBMCs from AHB patients}

The incidence of AHB is extremely low ( $<4.4$ per 100,000 population) [22-25], making it difficult to conduct clinical studies. So AHB is always less understood as compared with chronic HBV infection and the contribution of innate immunity to the control of AHB is even less reported. Varicella is an acute and selflimited infectious disease caused by varicella zoster virus (VZV). VZV and HBV are both DNA viruses. However, in contrast to AHB, VZV infection of healthy people at any age is almost always self-limited. Therefore, we used patients with varicella as the control cases of AHB to compare differences in the expression of DNA sensors in PBMCs.

As shown in Fig.2A, only IFI16 expression was upregulated in AHB patients as compared with HCs and the other DNA sensors in AHB patients were strikingly downregulated (Fig.2B-F), analogous to the reduced innate immune responses in AHB patients in a previous study [26]. More interesting is, except IFI16, all the other DNA sensors in varicella were also significantly downregulated (Fig.2A-F). Despite elevated expression of IFI16, IFN- $\beta$ expression was not altered in AHB (Fig.2H), supporting the idea of lack of induction of IFN-Is in AHB[26]. These results suggest HBV can be sensed by IFI16 in acute HBV infection and counteract the induction of IFN- $\beta$ in PBMCs.

\section{IFI16 is mainly expressed in monocytes from $\mathrm{AHB}$ and $\mathrm{CHB}$ patients}

As enhanced IFI16 expression was involved in both $\mathrm{CHB}$ and $\mathrm{AHB}$, we next investigated the cellular source of IFI16. Previous studies suggested IFI16 is mainly expressed in the CD $14^{+}$monocyte lineage [2728]. Besides the monocyte lineage, lymphoid cell lines also constitutively express IFI16 but the expression is not affected by IFNs [27][29]. So, to compare IFI16 expression in immune cells, we divided PBMCs into monocytes and non-monocytes. As shown in Fig.3, IFI16 was mainly expressed in monocytes in HCs $(p<0.001)$ and its expression level was significantly upregulated in monocytes from AHB and CHB 
patients, suggesting that HBV can be sensed by monocytes which is in keeping with previous studies [30]. In addition, the IFI16 expression levels in PBMCs were significantly positively correlated with serum HBV DNA loads in CHB patients, as revealed from our previous studies [16]. Taken together, these findings imply that HBV can be sensed by monocytes and its infection can induce enhanced expression of IFI16 in monocytes in AHB and CHB patients.

\section{Stimulation of IFI16 expression by its ligand VACV ds 70 mer is attenuated in monocytes from CHB patients}

Although HBV infection resulted in enhanced expression of IFI16 and STING in CHB patients, we did not observe increased expression of IFN- $\beta$ in CHB patients accordingly. We speculate that the IFI16-STINGIFN- $\beta$ pathway may be suppressed by HBV in monocytes in CHB patients. Previous studies showed that as a ligand for IFI16, the VACV double-stranded DNA 70-base pairs motif (VACV ds 70mer) can potently induce IFN- $\beta$ in PBMCs and monocytes [31]. To confirm our speculation, PBMCs and monocytes were isolated from $\mathrm{HCs}$ and $\mathrm{CHB}$ patients and stimulated in vitro by VACV ds 70mer in order to assay the response of the IFI16-STING-IFN- $\beta$ pathway. As shown in Fig.4A-D, the expression of IFI16 and STING in PBMCs and monocytes from CHB patients was significantly attenuated as compared with HCs after 24 hours of stimulation by VACV ds 70mer. As a result, the IFN- $\beta$ response to VACV ds 70mer was severely suppressed in PBMCs and monocytes from CHB patient (Fig.4E,F). These results support our speculation that the response of IFI16-STING-IFN- $\beta$ pathway to HBV is suppressed in monocytes in CHB patients, consistent with the finding that HBV is recognized mainly by liver macrophages (Kupffer cells) but does not induce an interferon response [32].

\section{Discussion}

Capable of recognition of pathogenic DNA, the innate immune defense system composed of intracellular DNA sensors plays an important role in preventing intracellular infection of pathogens such as DNA viruses. However, their role in HBV infection is still largely unclear. Published studies have shown that early in acute infection, HBV is poorly sensed by the innate immunity and does not or weakly induce innate immune responses [3][26][33-34]. It incubates stealthily in the liver for several weeks until elicitation of adaptive immune responses. Little is known about the involvement of DNA sensors in the process of acute and chronic HBV infection in humans. Collectively, our results reveal that (i) HBV can be detected by DNA sensors in acute or chronic HBV-infected patients; (ii) IFI16 expression is enhanced in PBMCs from both AHB and CHB patients and it is mainly expressed in monocytes; (iii) the IFI16-STING pathway in monocytes is attenuated by HBV infection.

The intracellular recognition of HBV infection by DNA sensors is still less understood. Moreover, it remains controversial in whether HBV can be sensed by intracellular DNA sensors or actively evades from the sensing pathways. To address this issue, we first analyzed the expression of the STING-dependent DNA sensors in PBMCs from chronic HBV-infected patients. The results showed the expression of IFI16, 
DDX41, and MRE11 was enhanced in CHB, IT, and IA patients. Published data showed that IFI16 was closely related to the degree of liver inflammation in CHB patients [35]. Upregulated expression of IFI16 only in chronic hepatitis patients suggests it maybe associate with inflammation within the liver. In fact, IFI16, predominantly nuclear as a transcription activator, is now recognized as a DNA sensor that dually functions as inducer of IL-1 $\beta$ and IFN- $\beta$ through IFI16-inflammasome activation and STING, respectively [36][31]. IFI16 was found to be critical for inhibition of many viruses [37]. It was recently demonstrated that IFI16 could recognize and directly bind to HBV covalently closed circular DNA (cccDNA) via an interferon-stimulated response element (ISRE) in cccDNA in hepatocytic nuclei [38]. If this is the case, the enhanced expression of IFI16 in PBMCs occurs only with the blood exposure of cccDNA via inflammatory necrosis of hepatocytes, as HBV cccDNA only originates from hepatocytes, not from PBMCs [39]. This may explain why IFI16 expression in PBMCs is upregulated only in hepatitis patients. DDX41 and MRE11 were reported to serve as cytosolic dsDNA sensors by Liu's and Kawai's group, respectively [40-41]. DDX41, a member of the DEXDc helicase family, directly binds dsDNA and STING via its DEADc domain in dendritic cells and monocytes to trigger type I interferon responses earlier than IFI16 [40]. MRE11, functioning as a DNA damage sensor usually in the form of the MRN complex (MRE11, RAD50, and Nijmegen breakage syndrome 1 (NBS1)), binds with RAD50 and exogenous DNA to induce IFN-Is by promoting STING translocation from the endoplasmic reticulum to the Golgi apparatus. The DDX41 and MRE11 expression increased both in IT and IA patients, suggesting they were involved in chronic HBV infection. Although there is still no report concerning the role of DDX41 and MRE11 playing in HBV infection, other reports have shown that they are involved in control of virus infections [42-44]. Thus, further investigation of their roles in HBV infection is warranted. Although activation of the cGAS-STING pathway was demonstrated to be able to inhibit HBV replication in cell culture and mice [18-19][45-46], HBV could also actively suppress cGAS expression and function in vitro and humanized liver chimeric mice [46]. Our results showed cGAS expression level was not altered in chronic HBV patients, suggesting HBV may evade from cGAS sensing. In parallel with the increased expression of IFI16, DDX41, and MRE11, the adaptor STING expression was also enhanced in chronic HBV patients. But the induction of effector IFN- $\beta$ was not observed in chronic HBV patients, implying the DNA sensor-STING pathway is suppressed. This may be explained by Liu's report showing HBV polymerase blocked DNA-sensing pathways by disrupting k63-linked ubiquitination of STING [21]. Taken together, these data suggest HBV can be sensed by DNA sensors in PBMCs in chronic HBV-infected patients and support the notion that HBV plays an active role in evading and inhibiting innate immune responses [6].

Different from the expression profile of DNA sensors in chronic HBV infection, IFI16 was found to be the only upregulated DNA sensor in AHB patients, in accordance with a previous report which showed induced expression of the IFI16 gene in an acute HBV infection model of chimpanzees [33]. However, the other DNA sensors were significantly downregulated as compared with HCs. This is reminiscent of the report by Dunn in which he demonstrated that with abundant production of IL-10 in AHB patients, the responses of NK cells along with $\mathrm{CD} 4^{+}$and $\mathrm{CD} 8^{+} \mathrm{HBV}$-specific T-cells from PBMCs were reduced [26]. Interestingly, the varicella patients and AHB patients displayed a similar expression pattern of DNA sensors, except IFI16. Despite with severe liver injury and a rapid short-term drop in HBV DNA levels in 
these AHB patients, the STING and IFN- $\beta$ expression was not induced by acute HBV infection. The absence of a robust IFN-I response in AHB is in accordance with other studies [26][33]. Of note, the IFN- $\beta$ expression in varicella patients was significantly suppressed as compared with $\mathrm{HCs}$, which may be explained by the evidence that the IFN- $\beta$ expression is inhibited by VZV ORF47 kinase via preventing the IRF3 activation in VZV infected cells [47]. Taken together, these data suggest that HBV can be sensed by IFI16 and utilizes an immunosuppressive strategy to actively prevent innate immune responses in acute HBV infection.

Next, we determined the cellular source of IFI16. Early reports showed IFI16 was constitutively expressed in all CD34 $4^{+}$myeloid progenitor cells from human bone marrow and later exclusively on the CD $14^{+}$ monocytoid lineage [27]. IFI16 is present in peripheral blood monocytes and lymphocytes, but not in granulocytes. In lymphocytes, it is not regulated by IFN-a, IFN-y, and IL-6 [29]. In 2010, IFI16 was first described as a STING-dependent dsDNA sensor in monocytes and macrophages by Bowie's group [31]. Recently, Liang's group revealed that HBV was not sensed by the infected hepatocytes due to lack of DNA sensing machinery but could induce human peripheral macrophage activation [30]. Based on these data, we divided PBMCs into monocytes and non-monocytes by magnetic separation. Quantitative RT-PCR analyses revealed that IFI16, whether in HCs, the CHB group or the AHB group, is mainly expressed in monocytes. Furthermore, IFI16 expression in monocytes from both AHB and CHB patients was significantly upregulated as compared with that from HCs. These findings along with the data from the aforementioned studies indicate that HBV can be sensed by monocytes and its infection results in enhanced expression of IFI16 in monocytes from AHB and CHB patients.

Lastly, we investigated the response of the IFI16-STING pathway in monocytes to VACV ds 70mer, a ligand for IFI16, to further confirm the impact of HBV infection on IFN- $\beta$ expression. In concordance with the results from patients, the response of the IFI16-STING pathway to VACV ds 70mer was significantly attenuated in monocytes from CHB patients in comparison with HCs, suggesting this DNA sensing pathway is impaired in CHB patients. These data further support the view that HBV is not always invisible to innate immunity but has evolved strategies to actively counteract recognition by innate immunity [6].

Our study has some limitations. First, the expression of DNA sensors in PBMCs may not be representative of the expression profile in liver. So studies of the liver tissues should be included. Second, more cases of AHB patients are needed to verify the expression characteristics of these DNA sensors in AHB. Third, the response of the IFI16-STING pathway to VACV ds 70mer in monocytes from AHB patients was not assayed because of the difficulty of obtaining adequate specimens from AHB patients. So additional studies are warranted. Last, the detailed mechanism of suppression of the IFI16-STING pathway by HBV is needed to identify.

\section{Conclusions}

In summary, we investigated for the first time the role of the STING-dependent DNA sensors in humans with acute and chronic HBV infection. Our data show that HBV can be sensed by DNA sensors in PBMCs 
in acute or chronic HBV-infected patients and meanwhile HBV infection also suppresses the response of the DNA sensor-STING pathway in PBMCs and monocytes from CHB patients, which may facilitate the persistence of HBV infection. These findings increase our understanding of HBV immune pathogenesis and warrant further investigations to explore the profound mechanisms by which HBV suppresses the DNA sensing pathway.

\section{Abbreviations}

STING: stimulator of interferon genes; HBV: hepatitis B virus; IFI16: interferon gamma inducible protein 16; DDX41: DEAD-box polypeptide 41; MRE11: meiotic recombination 11 homolog A; DAl: DNA-dependent activator of IRFs; DNA-PK: DNA-dependent protein kinase; cGAS: cyclic GMP-AMP synthase; IFN-Is: type I interferons; PBMC: peripheral blood mononuclear cell; IT: immune-tolerant carriers; CHB: chronic hepatitis $B$; IA: inactive carriers; VZV: varicella; AHB: acute hepatitis B

\section{Declarations}

\section{Ethics approval and consent to participate}

This study was approved by the Ethical Committee of Shenzhen people's hospital (2015-06). All subjects signed written informed consent for their participation.

\section{Consent for publication}

All authors approved the final manuscript.

\section{Availability of data and materials}

All relevant data are provided in this current manuscript.

\section{Competing interests}

The authors declare no conflicts of interest.

\section{Funding}

This study was supported by the Committee of Innovation of Science and Technology of Shenzhen (No. JCYJ20150403101028209).

\section{Authors' Contributions}

XYZ and HTC designed the study. HTC performed the experiment and wrote the manuscript. HTC, GRH, and $\mathrm{YC}$ performed data analysis. All authors read and approved the final manuscript.

\section{Acknowledgments}


We thank all the participants in the current study. We thank Dr. Yaying Zhou for flow cytometric analysis.

\section{References}

1. Aparna S, Johannes H, Mikolajczyk RT, Gérard K, Ott JRJ. Estimations of worldwide prevalence of chronic hepatitis B virus infection: a systematic review of data published between 1965 and 2013. Lancet. 2015;386:1546-55.

2. Lai CL, Ratziu V, Yuen MF, Poynard T. Viral hepatitis B. Lancet. 2003;362:2089-94.

3. Wieland SF, Chisari FV. Stealth and cunning: hepatitis B and hepatitis C viruses. J Virol. 2005 Aug;79:9369-80.

4. Suslov A, Boldanova T, Wang X, Wieland S, Heim MH. Hepatitis B Virus Does Not Interfere With Innate Immune Responses in the Human Liver. Gastroenterology. 2018;154.

5. Hong-Yan, Xiao-Yong, Zhang. Innate immune recognition of hepatitis B virus. World Journal of Hepatology. 2015;7:2319-22.

6. Ferrari C. HBV and the immune response. Liver Int. 2015 Jan;35 Suppl 1:121-8.

7. Dempsey A, Bowie AG. Innate immune recognition of DNA: A recent history. Virology. 2015 May;479480:146-52.

8. Paludan SR, Bowie AG. Immune sensing of DNA. Immunity. 2013 May 23;38:870-80.

9. Cai X, Chiu YH, Chen ZJ. The cGAS-cGAMP-STING pathway of cytosolic DNA sensing and signaling. Mol Cell. 2014 Apr 24;54:289-96.

10. Liu S, Cai X, Wu J et al. Phosphorylation of innate immune adaptor proteins MAVS, STING, and TRIF induces IRF3 activation. Science. 2015 Mar 13;347:aaa2630.

11. Zhang C, Shang G, Gui X, Zhang X, Bai XC, Chen ZJ. Structural basis of STING binding with and phosphorylation by TBK1. Nature. 2019 Mar;567:394-8.

12. Li Y, Wilson HL, Kiss-Toth E. Regulating STING in health and disease. J Inflamm (Lond). 2017;14:11.

13. Stempel M, Chan B, Brinkmann MM. Coevolution pays off: Herpesviruses have the license to escape the DNA sensing pathway. Med Microbiol Immunol. 2019 Aug;208:495-512.

14. Unterholzner L, Almine JF. Camouflage and interception: how pathogens evade detection by intracellular nucleic acid sensors. Immunology. 2019 Mar;156:217-27.

15. Scutts SR, Ember SW, Ren H et al. DNA-PK Is Targeted by Multiple Vaccinia Virus Proteins to Inhibit DNA Sensing. Cell Rep. 2018 Nov 13;25:1953-65 e4.

16. Chen H, He G, Chen Y, Zhang X, Wu S. Differential Activation of NLRP3, AIM2, and IFI16 Inflammasomes in Humans with Acute and Chronic Hepatitis B. Viral Immunol. 2018 Nov;31:639-45.

17. Terrault NA, Bzowej NH, Chang KM et al. AASLD guidelines for treatment of chronic hepatitis $B$. Hepatology. 2016 Jan;63:261-83. 
18. Dansako H, Ueda $\mathrm{Y}$, Okumura N et al. The cyclic GMP-AMP synthetase-STING signaling pathway is required for both the innate immune response against HBV and the suppression of HBV assembly. FEBS J. 2016 Jan;283:144-56.

19. He J, Hao R, Liu D et al. Inhibition of hepatitis B virus replication by activation of the CGAS-STING pathway. J Gen Virol. 2016 Dec;97:3368-78.

20. Chen QY, Liu YH, Li JH, Wang ZK, Liu JX, Yuan ZH. DNA-dependent activator of interferon-regulatory factors inhibits hepatitis B virus replication. World J Gastroenterol. 2012 Jun 14;18:2850-8.

21. Liu Y, Li J, Chen J et al. Hepatitis B virus polymerase disrupts K63-linked ubiquitination of STING to block innate cytosolic DNA-sensing pathways. J Virol. 2015 Feb;89:2287-300.

22. Su WJ, Liu CC, Liu DP et al. Effect of age on the incidence of acute hepatitis B after 25 years of a universal newborn hepatitis B immunization program in Taiwan. J Infect Dis. 2012 Mar 1;205:75762.

23. Sagnelli E, Sagnelli C, Pisaturo M, Macera M, Coppola N. Epidemiology of acute and chronic hepatitis B and delta over the last 5 decades in Italy. World J Gastroenterol. 2014 Jun 28;20:7635-43.

24. Duffell EF, van de Laar MJ, Amato-Gauci AJ. Enhanced surveillance of hepatitis B in the EU, 20062012. J Viral Hepat. 2015 Jul;22:581-9.

25. Hyun Kim B, Ray Kim W. Epidemiology of Hepatitis B Virus Infection in the United States. Clin Liver Dis (Hoboken). 2018 Jul;12:1-4.

26. Dunn C, Peppa D, Khanna $P$ et al. Temporal analysis of early immune responses in patients with acute hepatitis B virus infection. Gastroenterology. 2009 Oct;137:1289-300.

27. Dawson MJ, Elwood NJ, Johnstone RW, Trapani JA. The IFN-inducible nucleoprotein IFI 16 is expressed in cells of the monocyte lineage, but is rapidly and markedly down-regulated in other myeloid precursor populations. J Leukoc Biol. 1998 Oct;64:546-54.

28. Bourette RP, Mouchiroud G. The biological role of interferon-inducible P204 protein in the development of the mononuclear phagocyte system. Front Biosci. 2008 Jan 1;13:879-86.

29. Dawson MJ, Trapani JA. IFI 16 gene encodes a nuclear protein whose expression is induced by interferons in human myeloid leukaemia cell lines. J Cell Biochem. 1995 Jan;57:39-51.

30. Cheng X, Xia Y, Serti E et al. Hepatitis B virus evades innate immunity of hepatocytes but activates cytokine production by macrophages. Hepatology. 2017 Dec;66:1779-93.

31. Unterholzner L, Keating SE, Baran M et al. IFI16 is an innate immune sensor for intracellular DNA. Nat Immunol. 2010 Nov;11:997-1004.

32. Hosel $M$, Quasdorff $M$, Wiegmann $K$ et al. Not interferon, but interleukin- 6 controls early gene expression in hepatitis B virus infection. Hepatology. 2009 Dec;50:1773-82.

33. Wieland S, Thimme R, Purcell RH, Chisari FV. Genomic analysis of the host response to hepatitis $B$ virus infection. Proc Natl Acad Sci U S A. 2004 Apr 27;101:6669-74.

34. Stacey AR, Norris PJ, Qin L et al. Induction of a striking systemic cytokine cascade prior to peak viremia in acute human immunodeficiency virus type 1 infection, in contrast to more modest and 
delayed responses in acute hepatitis B and C virus infections. J Virol. 2009 Apr;83:3719-33.

35. Pang X, Li X, Mo Z et al. IFI16 is involved in HBV-associated acute-on-chronic liver failure inflammation. BMC Gastroenterol. 2018 May 9;18:61.

36. Kerur N, Veettil MV, Sharma-Walia N et al. IFI16 acts as a nuclear pathogen sensor to induce the inflammasome in response to Kaposi Sarcoma-associated herpesvirus infection. Cell Host Microbe. 2011 May 19;9:363-75.

37. Dell'Oste V, Gatti D, Giorgio AG, Gariglio M, Landolfo S, De Andrea M. The interferon-inducible DNAsensor protein IFI16: a key player in the antiviral response. New Microbiol. 2015 Jan;38:5-20.

38. Yang Y, Zhao X, Wang Z et al. Nuclear Sensor Interferon-Inducible Protein 16 Inhibits the Function of Hepatitis B Virus Covalently Closed Circular DNA by Integrating Innate Immune Activation and Epigenetic Suppression. Hepatology. 2019 Aug 12.

39. Kock J, Theilmann L, Galle P, Schlicht HJ. Hepatitis B virus nucleic acids associated with human peripheral blood mononuclear cells do not originate from replicating virus. Hepatology. 1996 Mar;23:405-13.

40. Zhang Z, Yuan B, Bao M, Lu N, Kim T, Liu YJ. The helicase DDX41 senses intracellular DNA mediated by the adaptor STING in dendritic cells. Nat Immunol. 2011 Sep 4;12:959-65.

41. Kondo T, Kobayashi J, Saitoh T et al. DNA damage sensor MRE11 recognizes cytosolic doublestranded DNA and induces type I interferon by regulating STING trafficking. Proc Natl Acad Sci U S A. 2013 Feb 19;110:2969-74.

42. Liu J, Huang Y, Huang X et al. Grouper DDX41 exerts antiviral activity against fish iridovirus and nodavirus infection. Fish Shellfish Immunol. 2019 Aug;91:40-9.

43. Stavrou S, Aguilera AN, Blouch K, Ross SR. DDX41 Recognizes RNA/DNA Retroviral Reverse Transcripts and Is Critical for In Vivo Control of Murine Leukemia Virus Infection. MBio. 2018 Jun 5;9.

44. Fullam A, Schroder M. DExD/H-box RNA helicases as mediators of anti-viral innate immunity and essential host factors for viral replication. Biochim Biophys Acta. 2013 Aug;1829:854-65.

45. Imai H, Dansako H, Ueda Y, Satoh S, Kato N. Daunorubicin, a topoisomerase II poison, suppresses viral production of hepatitis $B$ virus by inducing cGAS-dependent innate immune response. Biochem Biophys Res Commun. 2018 Oct 12;504:672-8.

46. Verrier ER, Yim SA, Heydmann L et al. Hepatitis B Virus Evasion From Cyclic Guanosine Monophosphate-Adenosine Monophosphate Synthase Sensing in Human Hepatocytes. Hepatology. 2018 Nov;68:1695-709.

47. Vandevenne $\mathrm{P}$, Lebrun $\mathrm{M}, \mathrm{El}$ Mjiyad $\mathrm{N}$ et al. The varicella-zoster virus ORF47 kinase interferes with host innate immune response by inhibiting the activation of IRF3. PLoS One. 2011 Feb 9;6:e16870.

\section{Figures}



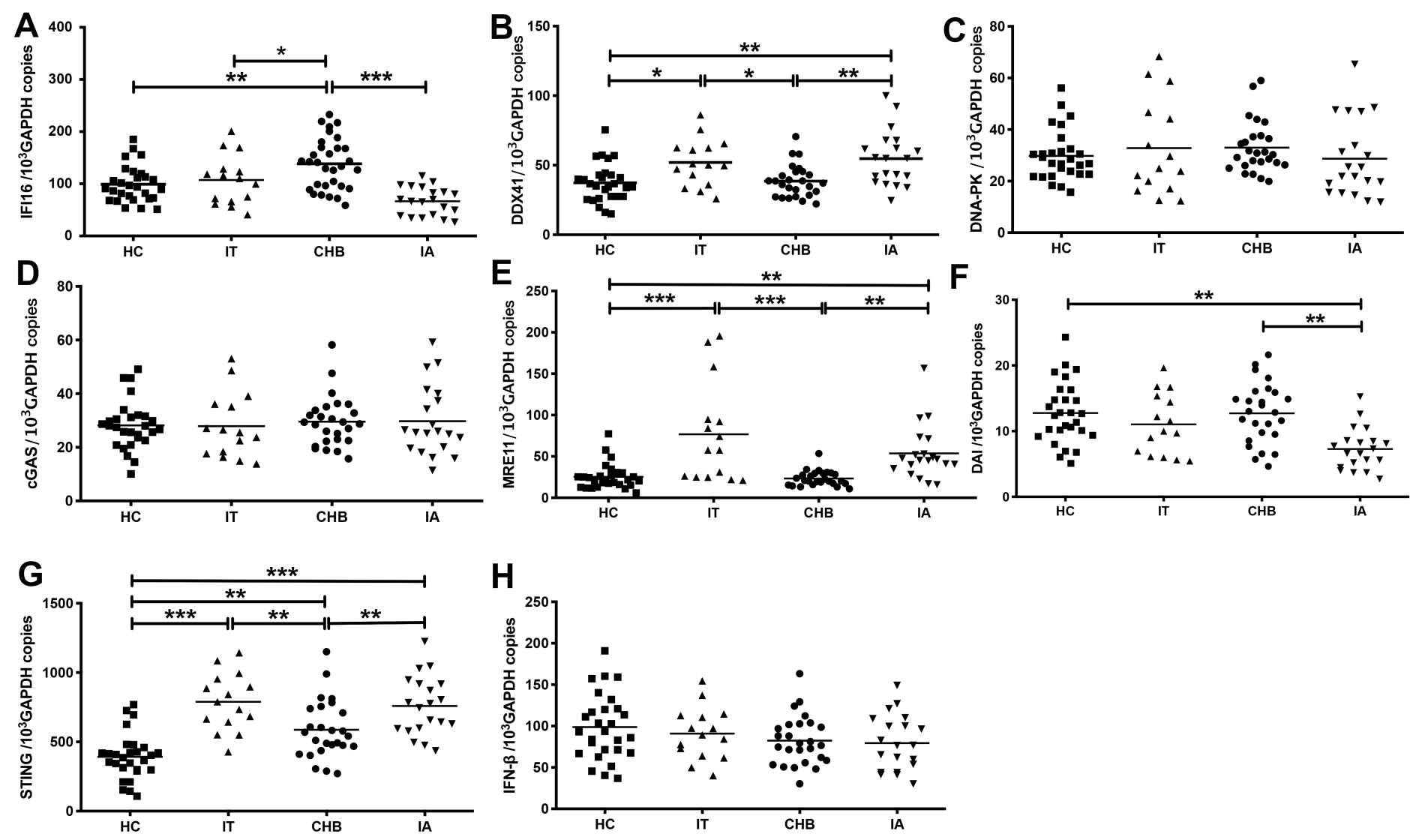

Figure 1

Expression of DNA sensors in PBMCs in chronic HBV-infected patients. The amounts of IFI16, DDX41, DNA-PK, cGAS, MRE11, DAI, STING, and IFN- $\beta$ mRNA were quantified using qPCR (A-H). One-way ANOVA was used to compare the differences among the four groups, followed by the Bonferroni post hoc test. * $p$ $<0.05,{ }^{\star *} p<0.01,{ }^{\star \star *} \mathrm{p}<0.001$. HC: healthy controls; IT: immune tolerant carriers; CHB: chronic hepatitis B patients; IA: inactive carriers. 

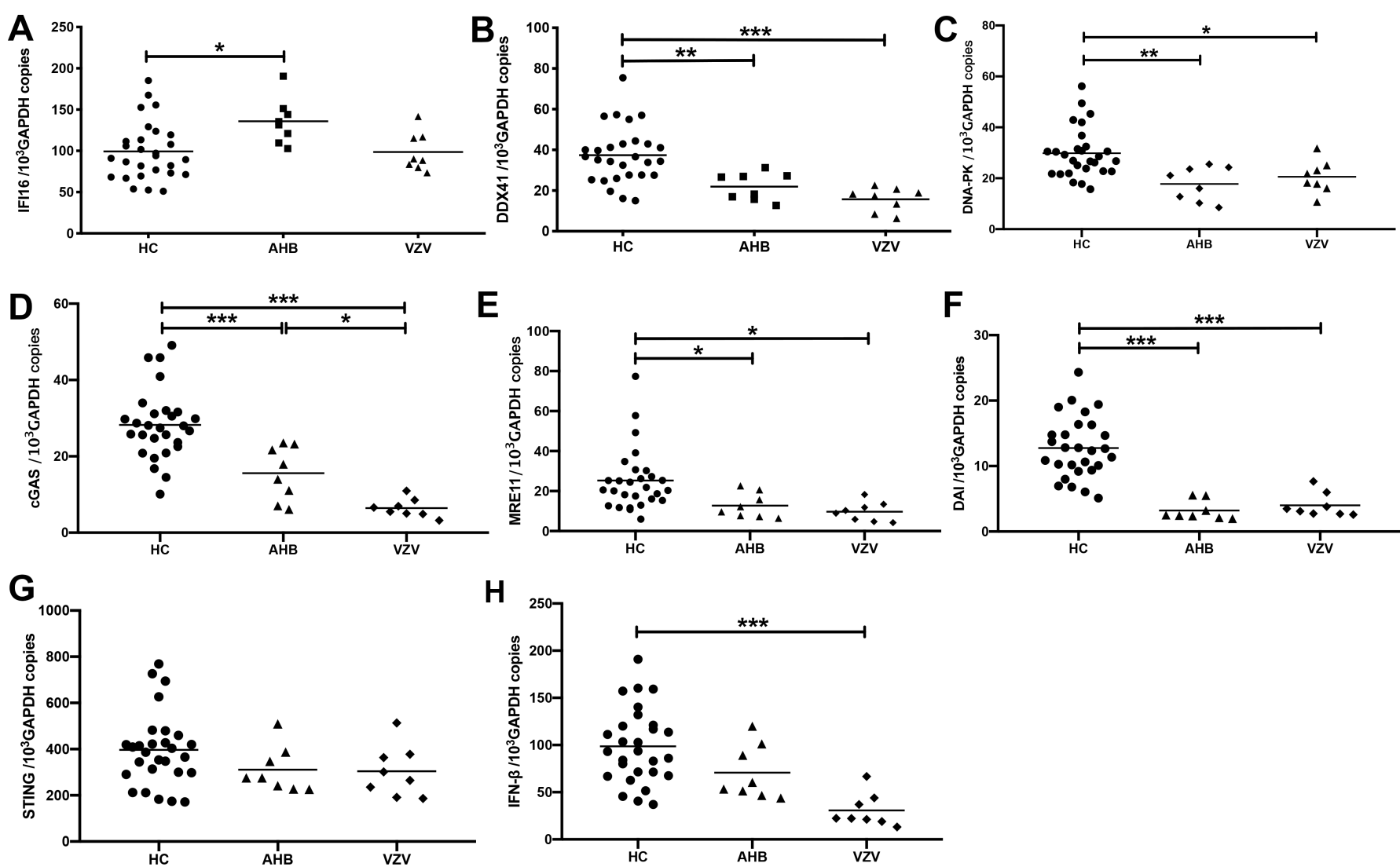

Figure 2

Expression of DNA sensors in PBMCs in acute HBV-infected patients. The amounts of IFI16, DDX41, DNAPK, cGAS, MRE11, DAI, STING, and IFN- $\beta$ mRNA were quantified using qPCR (A-H). One-way ANOVA was used to compare the differences among the three groups, followed by the Bonferroni post hoc test. * $\mathrm{p}<$ $0.05,{ }^{\star *} \mathrm{p}<0.01,{ }^{\star \star *} \mathrm{p}<0.001$. HC: healthy controls; AHB: acute hepatitis B patients; VZV: varicella patients. 


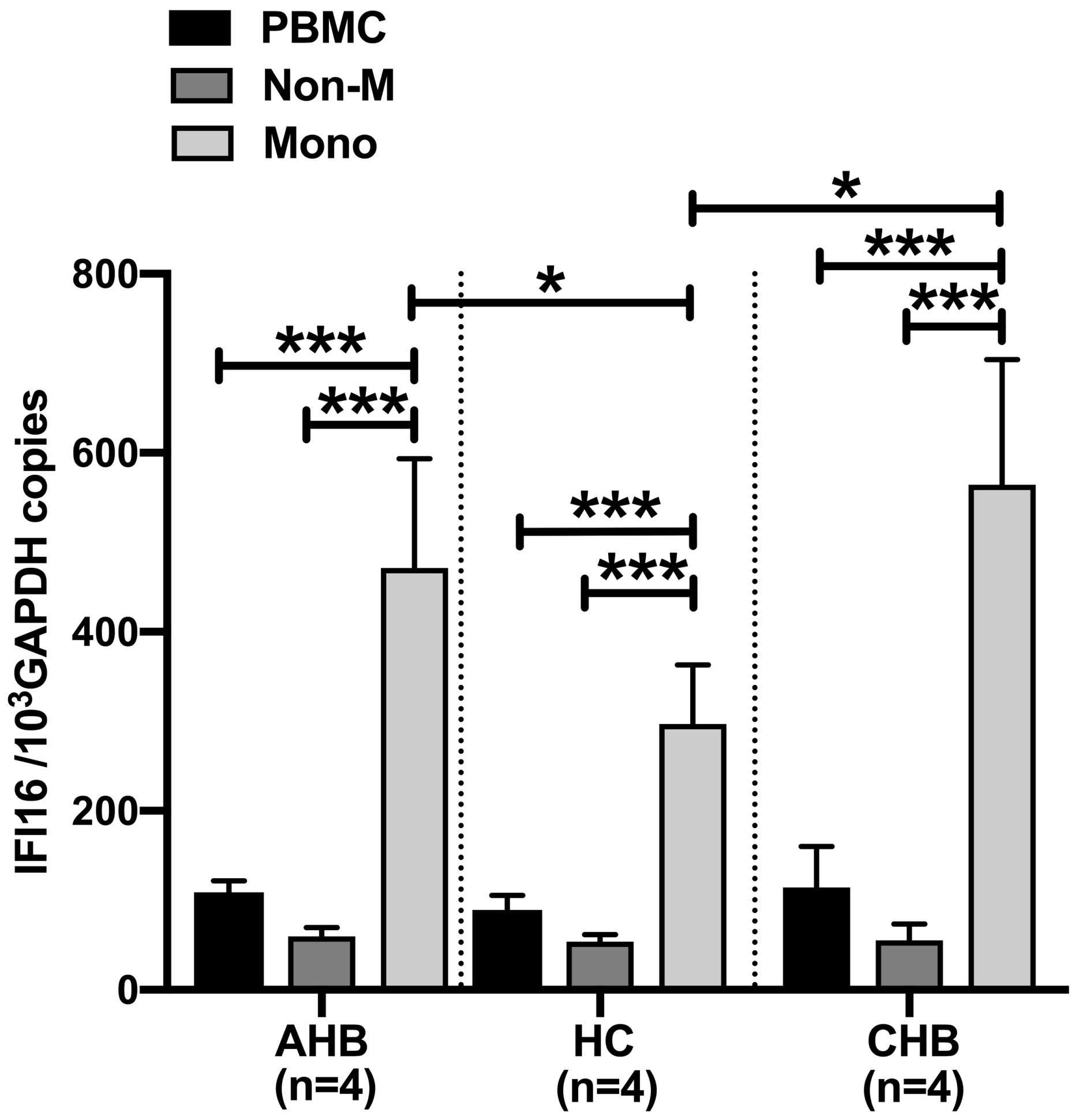

Figure 3

IFI16 expression in PBMCs, monocytes, and non-monocytes. IFI16 mRNA expression was determined by qPCR. HC: healthy controls; AHB: acute hepatitis B patients; CHB: chronic hepatitis B patients. Statistical analyses were performed using a Student's t test. ${ }^{*} p<0.05,{ }^{* \star} p<0.01, * \star \star p<0.001$. 

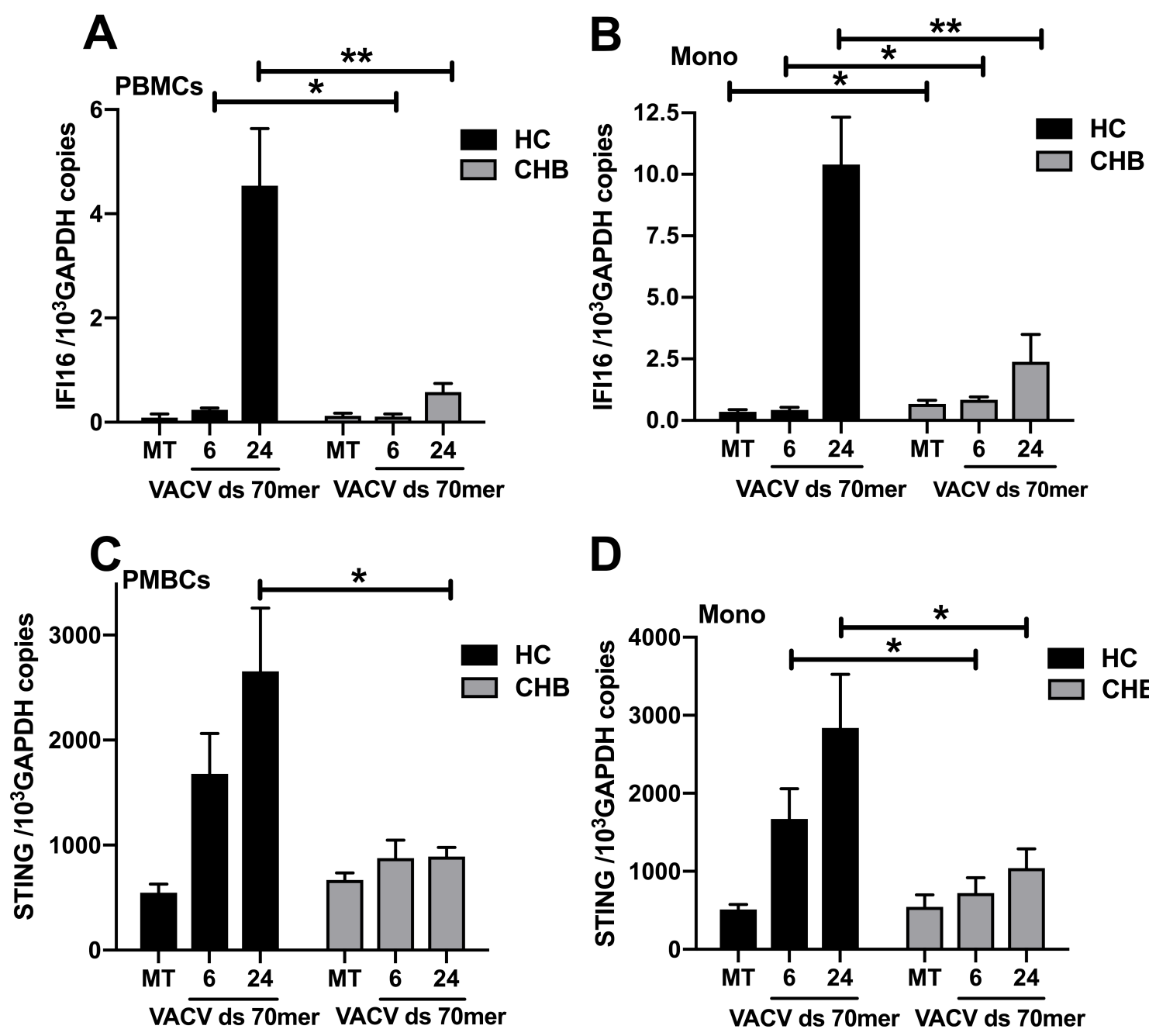

D

$\mathrm{HC}$
$\mathrm{CHB}$

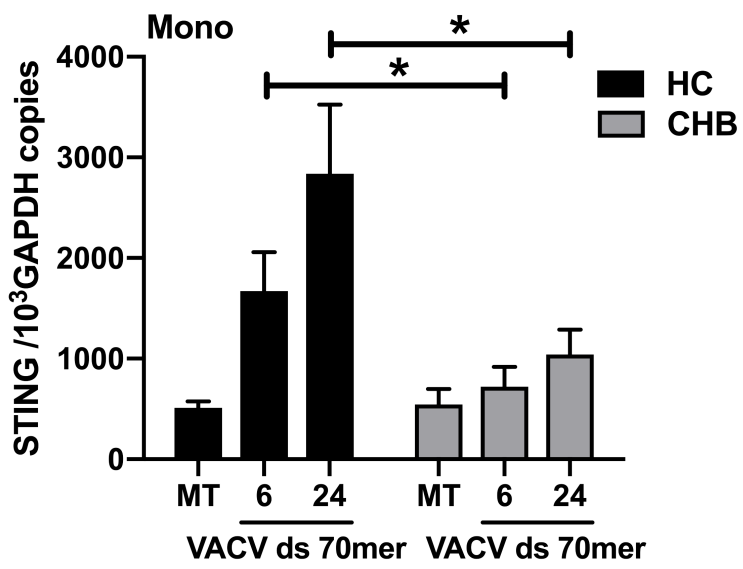

E

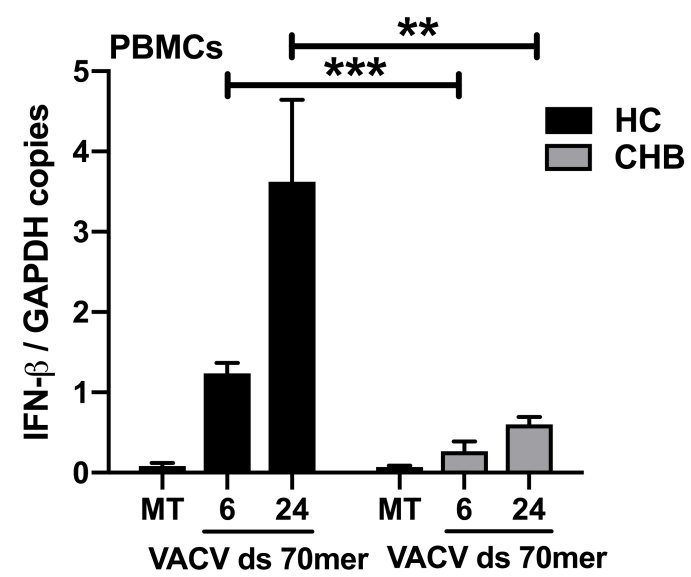

F

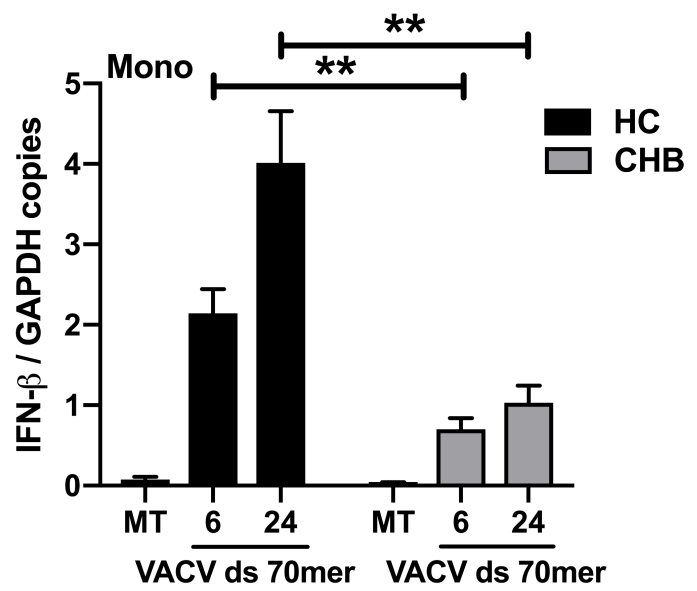

Figure 4

Stimulation of IFI16 expression by VACV ds 70mer is attenuated in PBMCs and monocytes from CHB patients. PBMCs and monocytes from CHB patients were mock transfected (MT) or transfected for 6 or $24 \mathrm{~h}$ with $2 \mu \mathrm{g} / \mathrm{mL}$ of VACV ds 70mer. The transcripts of IFI16, STING, and IFN- $\beta$ were then measured by qPCR $(A-F)$. Data depicted represent mean \pm SD of five independent patients from one of two 
experiments showing similar results. Statistical analyses were performed using a Student's t test. * $\mathrm{p}<$ $0.05,{ }^{*} \mathrm{p}<0.01,{ }^{* \star} \mathrm{p}<0.001$. HC: healthy controls; CHB: chronic hepatitis B patients. 